\title{
REVISTA ESPAÑOLA DE DERECHO CONSTITUCIONAL
}

DIRECTOR: FrANCISCO RUBIO LLORENTE

SECRETARIO: JuAN LUIS REQUeJo Pages

\section{ESTUDIOS}

\author{
Sumario del Año 18, Número 54 (septiembre-diciembre 1998)
}

- Peter Häberle, La protección constitucional y universal de los bienes culturales. Un análisis comparativo.

- Giancarlo Rolla, Las perspectivas de los derechos de la persona a la luz de las recientes tendencias constitucionales.

- José Ángel Marín Gámez, Reflexiones sobre la eutanasia: Una cuestión pendiente del derecho constitucional a la vida.

- Javer Donalae Villa, El Tratado de Amsterdam y la Constitución.

NOTAS

- José Luis López Trinío, Una revisión de la soberanía del Parlamento británico.

\section{JURISPRUDENCIA}

- Actividad del Tribunal Constitucional: Relación de sentencias dictadas durante el segundo cuatrimestre de 1998 (Departamento de Derecho Constitucional de la Universidad Carlos III de Madrid).

- La doctrina del Tribunal Constitucional durante el segundo cuatrimestre de 1998.

\section{ESTUDIOS CRÍTICOS}

- Luis Maria Diez-Picazo, El Derecho comunitario en la jurisprudencia constitucional española.

- Gabriel Bouzat, La argumentación jurídica en el control constitucional la propósito de la Sentencia 24-493 de la Corte Suprema Argentina, caso lachemet, $M^{a} L$. vs. Armada Argentina).

- Juan Antonio toscano Ontega, Un balance general de la jurisprudencia constitucional sobre el contenido de la Ley de Presupuestos Generales del Estado: a propósito de la STC 61/1997 (Ley del Suelo).

- Maria Ángeles Ahumada Ruiz, City of Boerne v. Flores: La importancia del "Candor Judicial".

\section{CRÍTICA DE LIBROS}

- Manuel Aragón Reyes, la inviolabilidad del domicilio.

- Miguel Sánchez Morón, L'erompere delle autoritá amministrative independenti.

- Alfonso Garcí Figueroa, Constitucionalismo y positivismo.

- Maria Bemdo Barrionuevo, La responsabilidad de los Estados por infracción del Derecho comunitario.

\section{RESEÑA BIBLIOGRÁFICA}

- Noticias de Libros.

- Revista de Revistas.

\section{PRECIOS DE SUSCRIPCIÓN ANUAL}

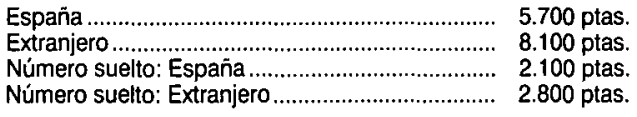

Suscripciones y números:

CENTRO DE ESTUDIOS POLIITICOS Y CONSTITUCIONALES

Fuencarral, $45-60^{\circ}$

28004 MADRID 


\section{REVISTA DE ADMINISTRACIÓN PÚBLICA}

DiREctor: Eduaroo García de Enterría

SECRETARIA: Carmen Chinchilla Marin

Sumario del número 147 (septiembre-diciembre 1998)

\section{ESTUDIOS}

S. Martín-Retortlllo Baquer, De la simplificación de la Administración Pública.

J. Befmejo Vera, La Administración inspectora.

J. L. Carao Fernández-Valmayor, El debate sobre la autonomía municipal.

A. A. Pérez Anores, La ordenación del territorio, una encrucijada de competencias planificadoras.

\section{JURISPRUDENCIA}

\section{COMENTARIOS MONOGRÁFICOS}

O. Herraiz Serrano, El paso firme dado por el Tribunal Superior de Justicia de Aragón en el duro "batallar" por la tutela cautelar: La aplicación de la técnica francesa del "référé provision" (Comentario al Auto de la Sala de lo ContenciosoAdministrativo de 26 de febrero de 1998).

M. MoReno Rebato, Circulares, instrucciones y órdenes de servicio: Naturaleza y régimen jurídico.

J. V. MoRote SARRión, La novedosa doctrina del Tribunal Constitucional sobre el cómputo del plazo de prescripción de la acción de responsabilidad extracontractual de la Administración.

II. NOTAS

Contencioso-administrativo.

A) En general (T. Font I LLOVET Y J. TORNos MAS).

B) Personal (R. Entrena Cuesta).

CRÓNICA ADMINISTRATIVA

BIBLIOGRAFÍA

\section{PRECIOS DE SUSCRIPCIÓN ANUAL}

\begin{tabular}{|c|c|}
\hline 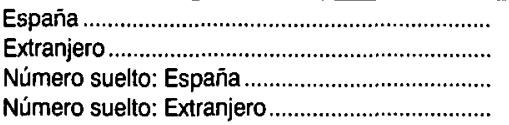 & $\begin{array}{l}6.100 \text { ptas. } \\
8.600 \text { ptas. } \\
2.200 \text { ptas. } \\
3.200 \text { ptas. }\end{array}$ \\
\hline $\begin{array}{c}\text { ITRO DE ESTUDIOS POLíIICOS Y CONS } \\
\text { Fuencarral, } 45 \\
28004 \text { MADRID }\end{array}$ & \\
\hline
\end{tabular}




\title{
Rivista di Politica Economica
}

\author{
SOMMARIO
}

\section{$\underline{S A G G I}$}

Distribuzione del reddito, prezzi e quantità prodotte nella impostazione classica. Un commento a Caravale e D'Orlando

Marco Piccioni

Regola Ss in un'economia aperta ed il pass-through puzzle in Italia. 25 Roberta Cuccio

Limiti del microfondamenti della ipotesi di instabilità finanziaria: una prospettiva di superamento

\section{Gennaro Corbisiero}

\section{TEMA DEL MESE}

L'avvio della terza fase dell'unione monetaria europea e l'introduzione dell'euro: quali implicazioni per l'informazione statistica?. 103 Enrico Giovannini

\section{RASSEGNA BIBLIOGRAFICA}

\section{Analisi d'opera}

Spagnolo, L. V., La convergenza di Maastricht: una misura della divergenza ............................................................................... 149

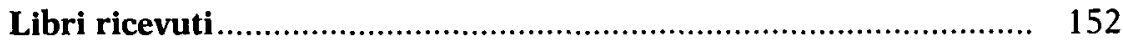


Gabriel Tortella (Presidente)

\section{PATRONATO}

Carmen Iglesias (Directora del Centro de Estudios Constitucionales)

Carlos Pascual (Director de Marcial Pons)

Francisco Prada Gayoso (Director de la Fundación Empresa Pública)

Leandro Prados de la Escosura (Universidad Carlos III)

Felipe Ruiz Martín (Presidente Honorario de la Asociación de Historia Económica) 


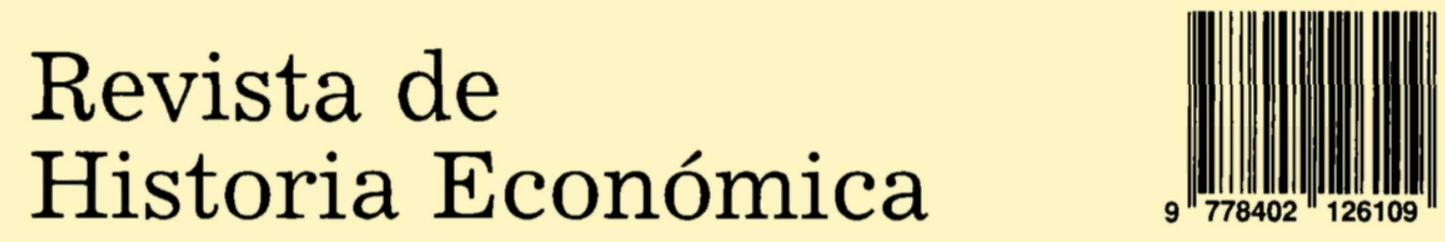

